University of Wollongong

Research Online

Australian Institute for Innovative Materials -

Papers

Australian Institute for Innovative Materials

$1-1-2020$

On the Degradation of Retained Austenite in Transformation Induced Plasticity Steel

Ilana Timokhina

Azdiar Adil Gazder

University of Wollongong, azdiar@uow.edu.au

Jiangting Wang

Ilias Bikmukhametov

Peter Hodgson

See next page for additional authors

Follow this and additional works at: https://ro.uow.edu.au/aiimpapers

Part of the Engineering Commons, and the Physical Sciences and Mathematics Commons

Research Online is the open access institutional repository for the University of Wollongong. For further information contact the UOW Library: research-pubs@uow.edu.au 


\title{
On the Degradation of Retained Austenite in Transformation Induced Plasticity Steel
}

\author{
Abstract \\ (C) 2020, The Minerals, Metals \& Materials Society and ASM International. A transformation-induced \\ plasticity steel was thermomechanically processed and then transformed to bainite at an isothermal \\ transformation temperature of $723 \mathrm{~K}$ for 1800 seconds, which exceeds the time required for completion \\ of the bainite transformation. The formation of lenticular-shaped carbides with a triclinic lattice and \\ internal substructure was found after thermomechanical processing. After 16 years of storage at room \\ temperature, the decomposition of retained austenite into pearlite was observed for the first time at this \\ temperature.

\section{Disciplines} \\ Engineering | Physical Sciences and Mathematics

\section{Publication Details} \\ Timokhina, I., Gazder, A., Wang, J., Bikmukhametov, I., Hodgson, P., Niessen, F. \& Pereloma, E. (2020). On \\ the Degradation of Retained Austenite in Transformation Induced Plasticity Steel. Metallurgical and \\ Materials Transactions A: Physical Metallurgy and Materials Science,

\section{Authors} \\ Ilana Timokhina, Azdiar Adil Gazder, Jiangting Wang, Ilias Bikmukhametov, Peter Hodgson, Frank Niessen, \\ and Elena V. Pereloma
}




\section{On the degradation of retained austenite in transformation induced plasticity steel.}

Ilana B. Timokhinaa, Azdiar A. Gazderb, Jiangting Wanga, Ilias Bikmukhametovad, Peter D. Hodgson ${ }^{a}$, Frank Niessen ${ }^{b}$ Elena V. Perelomab,c

anstitute for Frontier Materials, Deakin University, Geelong, VIC 3220, Australia

bElectron Microscopy Centre, University of Wollongong, Wollongong, NSW 2500, Australia cSchool of Mechanical, Materials, Mechatronic and Biomedical Engineering, University of Wollongong, Wollongong, NSW 2522, Australia

dDepartment of Metallurgical \& Materials Engineering, The University of Alabama, Tuscaloosa, Alabama, 35487, USA

ilana.timokhina@deakin.edu.au, azdiar@uow.edu.au, jiangting.wang@deakin.edu.au, ibikmukhametov@ua.edu,peter.hodgson@deakin.edu.au,contact@fniessen.com, elenap@uow.edu.au

Corresponding author: ilana.timokhina@deakin.edu.au

\section{Abstract}

A transformation-induced plasticity steel was thermo-mechanically processed and then transformed to bainite at an isothermal transformation temperature of $723 \mathrm{~K}$ for $1800 \mathrm{~s}$, which exceeds the time required for completion of the bainite transformation. The formation of lenticular-shape carbides with a triclinic lattice and internal substructure was found after thermomechanical processing. After 16 years storage at room temperature the decomposition of retained austenite into pearlite was observed for the first time at this temperature.

Keywords: transformation-induced plasticity steel; retained austenite decomposition; atom probe tomography; pearlite formation at room temperature; transmission electron microscopy; electron back-scattering diffraction.

\section{Introduction}


Retained austenite (RA) is an important phase in many modern advanced high strength steels, such as Transformation-Induced Plasticity (TRIP) steels [1-5], nanobainitic steels [6-8], quenched and partitioned (Q\&P) steels [9-12] and medium-Mn steels [13-15]. In all of these steel grades, RA is the product of an incomplete bainite transformation due to the high $\mathrm{Si}$ concentration leading to the high carbon content of RA $[16,17]$. To a large extent, the carbon and manganese contents of the RA determine its chemical stability $[1,18,19]$. The microstructure and stability of the RA is important for production and in-service performance of components manufactured from the steel, as any changes in the microstructure (phase constituents, morphology, coarseness, etc.) have a direct effect on the mechanical properties (toughness, yield strength, crashworthiness, etc.). A high carbon concentration in the RA is desirable as it promotes stability on cooling and against the deformation-induced martensite transformation $[18,19]$. However, this also makes the RA more susceptible to decomposition into ferrite and carbides at elevated temperatures due to the increased driving force for carbides precipitation from austenite with higher carbon content [20]. The precipitation of carbides in bainite during early stages of the bainite transformation also leads to less stable RA and its transformation to martensite on subsequent cooling [21-23]. The stability of the RA is also somewhat related to its morphology, as it has been commonly reported that film-like RA between neighbouring subunits of bainitic ferrite (BF) has a higher carbon content compared to the blocky RA located between sheaves of bainite [20,24]. However, it was recently shown that blocky RA could have a high carbon content similar to film RA [25].

With the progress of the incomplete bainite transformation, the carbon enrichment of the RA increases until a critical level, at which the RA decomposition takes place. For example, this occurs when the holding time at isothermal transformation temperature exceeds the time required for the bainitic reaction [17]. Alternatively, for the same holding time, an increase in the isothermal bainite transformation temperature/tempering temperature will have a similar effect on the carbon content in the RA and result in accelerated RA decomposition [26, 27]. 
To-date, there is limited information available with respect to the mechanism of RA decomposition and on the types of carbides formed. Park et al. [26] reported that no decomposition of the RA was observed in a Fe-0.2C-2.Mn-1Si-1Al (wt.\%) TRIP steel after tempering at temperatures below $473 \mathrm{~K}$. However, at higher temperatures, the first precipitate to form in partially decomposed RA was $\varepsilon$-carbide followed by the precipitation of cementite. The latter became globular and spheroidised at longer holding times at high temperatures. On the other hand, in a medium Mn steel (Fe-0.1C-5Mn wt.\%) the RA decomposition was delayed to temperatures above $673 \mathrm{~K}$; blocky RA decomposed into ferrite and rod-like cementite at $723 \mathrm{~K}$. Similarly, the formation of cementite was only detected after tempering for 30 min or longer at 723K for a Fe-0.2C-3Mn-2Si wt.\% steel [23]. Full decomposition of the RA into ferrite and cementite was observed in both TRIP and nanobainitic steels after reheating and holding for 3 hrs at 723K [28]. Atom probe study of hot-worked tool steel showed a laminar arrangement of cementite after RA decomposition at 883K [22]. Another morphology of carbide formed on the decomposition of RA has been reported by Sandvik [29] in a 0.9C-2Si-0.5Mn-0.42Cr wt.\% steel at $653 \mathrm{~K}$, with $\sim 100 \mathrm{~nm}$ thick, lenticular plate-shaped carbides with a triclinic crystal lattice and a midrib.

To the best of the authors' knowledge, there have not been any studies to-date on RA stability during long term service life at ambient temperatures. In this work, this deficiency is addressed by studying the microstructure of thermo-mechanically processed TRIP steel [30] after more than 16 years in storage using a combination of transmission electron microscopy (TEM), electron back-scattering diffraction (EBSD), and atom probe tomography (APT).

\section{Material and Methods}

The nominal composition of the TRIP steel used in this study was Fe-0.21C-1.51Mn1.49Si- 0.004Mo - 0.01Al - 0.036Nb wt.\%.Thermo-mechanical processing (TMP) was 
undertaken on a laboratory rolling mill. The TMP schedule (Fig. 1) was constructed by utilising continuous-cooling-transformation data [31]. The strip was reheated in a $15 \mathrm{~kW}$ muffle furnace and soaked at $1523 \mathrm{~K}$ for $120 \mathrm{~s}$. After soaking, the strip was $25 \%$ rough rolled at $1373 \mathrm{~K}$

followed by a 120s hold to uniformly condition the recrystallised austenite. Subsequent $47 \%$ finish rolling in the non-recrystallised region was undertaken at $1123 \mathrm{~K}$ followed by cooling at 1 $\mathrm{K} \cdot \mathrm{s}^{-1}$ to the accelerated cooling start temperature of $943 \mathrm{~K}$ to form $\sim 50 \mathrm{vol} . \%$ of polygonal ferrite; which is the optimal amount required to stabilise the highest volume fraction of RA [32]. Following this, two spray guns were used to cool the strip at $\sim 20 \mathrm{~K} / \mathrm{s}$ to $773 \mathrm{~K}$ to avoid pearlite formation. At this point, coiling was simulated by lowering the strip into a fluid bed furnace, covering it with aluminium oxide sand and isothermally holding at $723 \mathrm{~K}$ for $1800 \mathrm{~s}$ to form bainite. Following this, the strip was quenched in an iced brine solution (Fig. 1). The final strip thickness was $\sim 6.5 \mathrm{~mm}$. The strip was produced in 2002 and kept in storage at room temperature (RT) for 16 years. This enables study of the effect of prolonged storage on the TRIP steel microstructure.

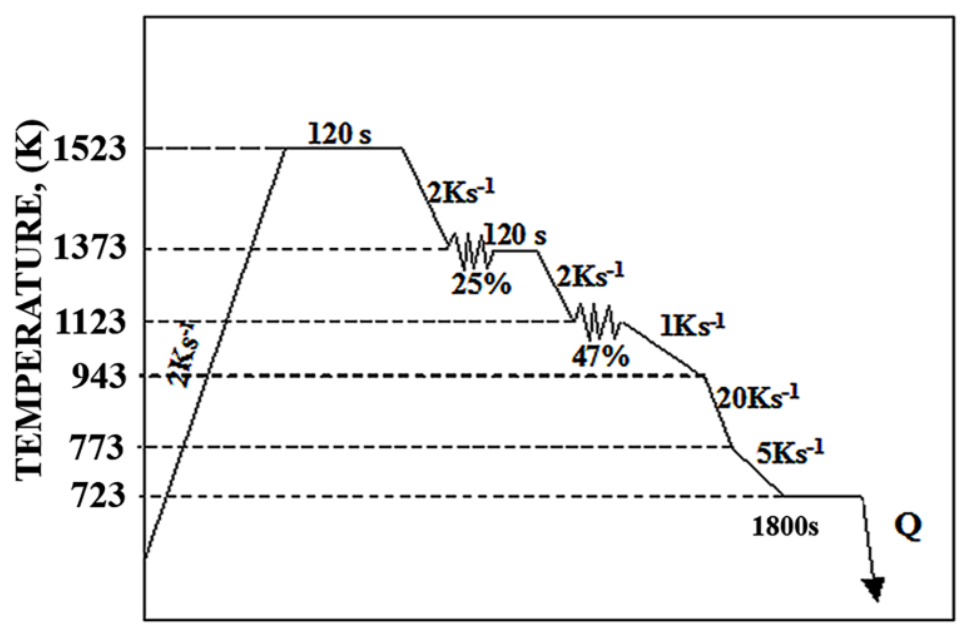

TIME, (s)

Figure 1. Thermomechanical processing schedule.

The volume fraction of RA was measured using a Philips PW 1130 diffractometer equipped with a $\mathrm{Ni}$-monochromated $\mathrm{Cu} \mathrm{K} \alpha$ radiation source operated at $40 \mathrm{keV}$ and $25 \mathrm{~mA}$ in Bragg-Brentano geometry. The relative intensities of the peaks were recorded by varying $2 \theta$ from $40^{\circ}-90^{\circ}$ in 
continuous scan mode at a rate of $0.5^{\circ} \mathrm{min}^{-1}$ with a step size of $0.05^{\circ}$. The volume fraction of RA

112 was estimated by the direct comparison method using the integrated intensities of the $(200)_{\alpha}$ and (211) $\alpha$ peaks from bcc ferrite and the $(200)_{\gamma}$ and (220) $)_{\gamma}$ peaks from fcc austenite [33]. Since the original strip was produced in 2002, electron backscattering diffraction (EBSD) maps of the microstructure after TMP was not carried out as this technique was not accessible at that time. However, the strip subjected to prolonged room temperature storage for 16 years, was mapped.

The samples for EBSD were cut from the centre of the aged strip width along the normal direction-rolling direction (ND-RD) and mechanically ground to $0.3 \mathrm{~mm}$ thickness using up to 1200 grit silicon carbide paper. $\emptyset 3 \mathrm{~mm}$ discs were punched out, after ensuring that each disc contained a short chord parallel to the $\mathrm{RD}$, in order to identify the macroscopic sample coordinates. The discs were manually ground to $\sim 70 \mu \mathrm{m}$ thickness using 2400 and 4000 grit silicon carbide papers, and then twin-jet electro-polished to produce electron transparent foils using a solution of $90 \%$ methanol and $10 \%$ perchloric acid in a Struers Tenupol-5 operated at $30 \mathrm{~V}, \sim 150 \mathrm{~mA}$ and $243 \mathrm{~K}$.

EBSD orientation and Energy Dispersive Spectroscopy (EDS) elemental data were obtained simultaneously from the centre of the ND-RD cross- section using a JEOL JSM-7001F field emission gun scanning electron microscope operated at $15 \mathrm{kV}$ accelerating voltage, $\sim 5.1 \mathrm{nA}$ probe current, $12 \mathrm{~mm}$ working distance at $\times 1000$ magnification. The microscope was fitted with a Nordlys-II(S) EBSD detector and an $80 \mathrm{~mm}^{2} \mathrm{X}$-Max EDS detector interfacing with the Oxford Instruments (OI) Aztec software suite. A step size of $0.06 \mu \mathrm{m}$ was employed such that a map comprising $2000 \times 1500$ pixels, which corresponds to an area of $20 \times 90 \mu \mathrm{m}^{2}$, was collected over $\sim 61.5$ hours.

The EBSD mapping conditions were optimised beforehand with a 16.33 ms camera exposure time, 43 and 32 reflectors employed for the bcc and fcc phases, respectively, $4 \times 4$ binning, 3 background frames, a Hough resolution of 60 . The speed of acquisition of the individual electron backscattering patterns was $13.5 \mathrm{~Hz}(\sim 73.9 \mathrm{~ms})$ with up to 11 Kikuchi bands concurrently 
indexed via the OI "Refined Accuracy" algorithm. The raw EBSD maps returned an overall indexing rate of $97.48 \%$ such that most of the zero solutions were concentrated at boundary interfaces.

EDS maps were obtained using a 0-20 keV energy range, 2048 channels, a process time of 3, a detector dead time of $50-55 \%$ and a pixel dwell time of $24.8 \mathrm{~ms}$. Over the full 'TruMap' area, the Fe-K, Mn-K, Si-K, C-K, Nb-L, Cu-L, Al-K and Mo-L lines returned distributions of relative frequency versus counts per second (cps) with maximum counts rounded-off to 1055, 232, 335, $225,119,57,670$ and 695 , respectively.

Post-processing of the EBSD maps were undertaken using the Oxford Instruments HKL Channel5 software suite. In brief, it involved the removal of wild spikes and cyclic extrapolation of zero solutions up to five neighbours followed by thresholding the band contrast histogram to delineate unindexable regions (Fig. 2a). Since the EBSD maps were indexed as iron fcc (austenite) and bcc (ferrite) during acquisition, a previously developed procedure using the OI Channel-5 software suite [34] was modified to initially segment the phases into austenite, polygonal ferrite, and an unsegmented fraction comprising bainite, a mixed region of martensite/pearlite and carbides. While a detailed step-by-step guide to segment polygonal ferrite from the unsegmented fraction is given in Ref. [34], a brief description of the procedure to segment bainite and the mixed region of martensite/pearlite and carbides is as follows. To segment the bainite and the mixed region of martensite/pearlite and carbides, the C-K EDS map data of that subset was imported as an *.tiff image into the Ilastik v3.1 software. Ilastik is an open source software for image classification and segmentation [35]. Using the in-built, machine learning pixel classification algorithms, the subset was segmented into an image comprising three grayscale colour thresholds for bainite, the mixed region of martensite/pearlite and carbides signifying lower, medium and highest carbon contents, respectively (Fig. 2b last carbonK map). A specifically written MATLAB script read and assigned the varying grayscale colours to individual pixels of the *.ctf file. Following this, the *.ctf file was re-imported back into OI 
Channel-5 and the varying grayscale colours assigned as separate phases; in order to colourcode the phase map (Fig. 2c phase map).

Bright field (BF), dark field (DF) and selected area electron diffraction (SAED) studies were undertaken on a Philips CM20, operated at $200 \mathrm{kV}$ to characterise the initial microstructure after TMP in 2002. Similar work was performed to study the strip after 16-year storage using a JEOL $2100 \mathrm{~F}$ operated at $200 \mathrm{kV}$. In both cases, electron transparent thin foils were prepared by twin-jet electro-polishing. Orientation distributions along BF layers were studied by SAED patterns using an aperture of $1.1 \mu \mathrm{m}$ nominal diameter.
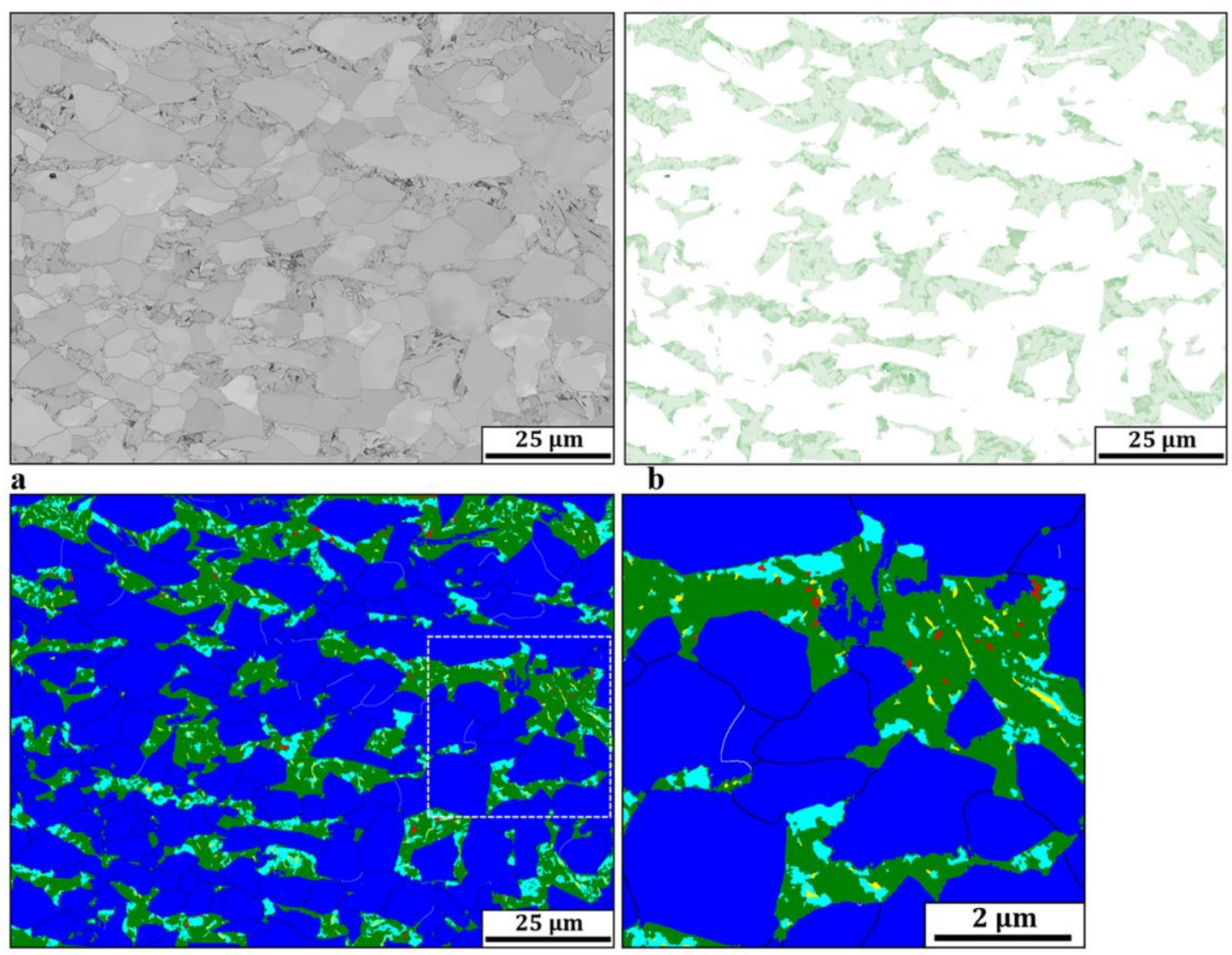

c

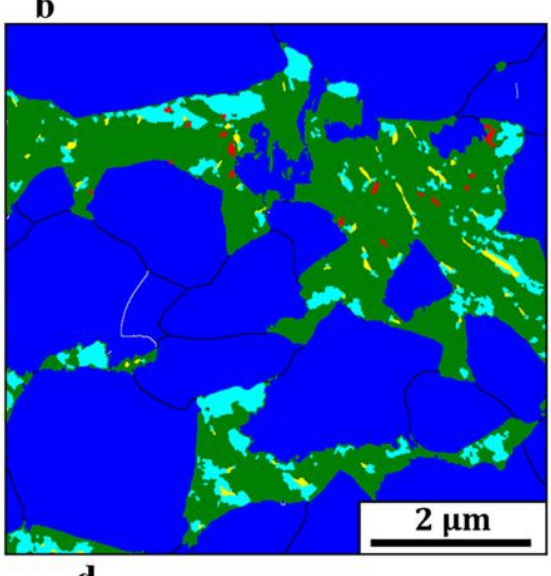

Figure 2. Representative (a) band contrast, (b) carbon $-K$ and (c) phase maps. In (b), the areas exclude polygonal ferrite and austenite. The area denoted by the white dashed rectangle in (c) is magnified in (d). In (c) and (d) red = austenite; blue = polygonal ferrite; green = ferrite in bainite; yellow $=$ carbides aqua $=$ mixed region $($ see text for details $)$. 
Atom probe tomography (APT) was used to study the variation in local chemical composition of the phases, solute redistribution and segregation across the phases [36]. APT needles were prepared from bulk polished sample and TEM foils using focused ion beam milling (FIB) in a dual beam FEG-SEM (FEI Quanta 3D). For example, pearlitic regions were identified and their location marked on the foil using TEM (Fig. 3). Following this, Pt supporting layers were deposited in the region of interest on both sides of the foil (Fig. 3b). The targeted specimens were then cut from the region of interest and lifted out on to an APT sample holder. Finally, APT needles were sharpened using the FIB operated at $30 \mathrm{kV}$ for initial shaping and $8 \mathrm{kV}$ for final polishing.

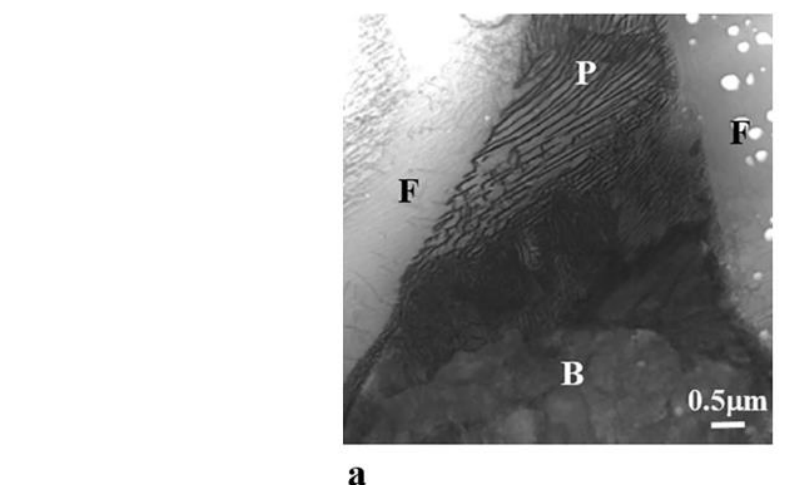

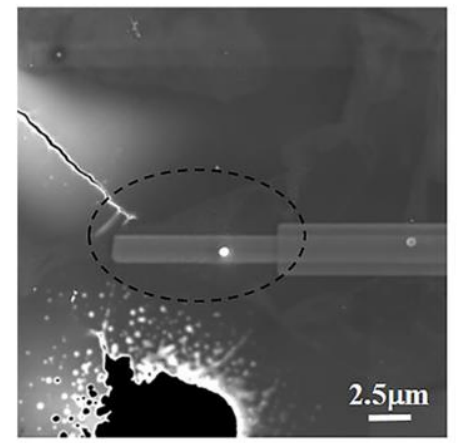

b

Figure 3. TEM micrograph (a) and position of APT sample (b) taken from pearlite shown in (a). F is ferrite, $\mathrm{P}$ is pearlite, $\mathrm{B}$ is bainite. Dash line outlines the pearlite region and APT sample taken from this area.

APT was conducted on a Cameca LEAP 5000 XR operated in voltage mode with a pulse rate of $200 \mathrm{kHz}$ and a sample temperature of $60 \mathrm{~K}$. Data reconstruction and quantitative analysis was undertaken within the IVAS 3.6.14 software suite [36]. Phase composition was determined from the regions without visible coarse particles, boundaries and/or defects.

Thermodynamic modelling was applied to assess the phase equilibrium for the local composition of RA at ambient temperature. The calculations were performed with Thermo-Calc 2020a [37] using the TCFE9 thermodynamics database [38]. 


\section{Results}

219 The microstructure after TMP comprised $\sim 50 \%$ of polygonal ferrite with layers of granular bainite and acicular ferrite (Fig. 4a). RA islands and films were located in-between polygonal ferrite grains, at interfaces between polygonal ferrite and BF, between BF laths and as martensite/RA constituent (Fig. 4). XRD confirmed that the steel contained 5\% RA. In addition, coarse, lenticular-shaped carbides (hereafter referred to as LSC) were detected in bainite between the BF laths (Fig. 4b). The morphology of LSC differed significantly from those seen previously in upper and lower bainite $[17,31]$ and they also contained a high density of internal faults (Figs. 4b-4d). The average size of LSC was estimated using their projected lengths in the $(111)_{\alpha}$ matrix plane such that they averaged $370 \pm 100 \mathrm{~nm}$ length and $100 \pm 30 \mathrm{~nm}$ width. Indexing their diffraction patterns showed that the LSC crystal structure was close to triclinic (or alternatively, distorted orthorhombic) with approximate lattice parameters of $\mathrm{a}=0.638 \mathrm{~nm}$, $\mathrm{b}=0.505 \mathrm{~nm}, \mathrm{c}=0.459 \mathrm{~nm}$, and $\alpha=90^{\circ}, \beta=70.1^{\circ}$ and $\gamma=84.7^{\circ}$ [29]. In some cases, TEM also revealed the presence of LSC near RA; an observation that could be ascribed to the partial decomposition of RA that leads to the formation of LSC and ferrite (Figs. 4c and 4d). TEM investigation showed that "recovered ferrite", or ferrite grains with dislocation density lower than that in BF but a higher than in PF (for example, the area marked by F in Fig. 4c), are present in the areas in close proximity to LSC, presumably as a result of the decomposition of RA.

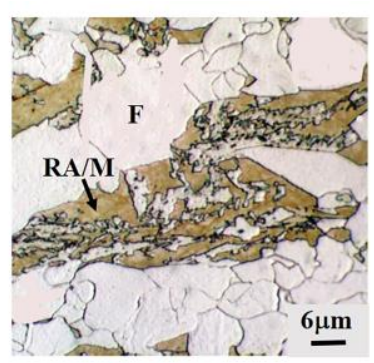

a

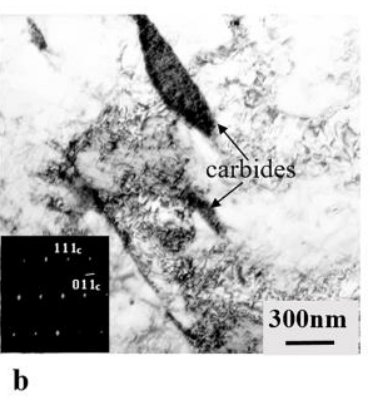

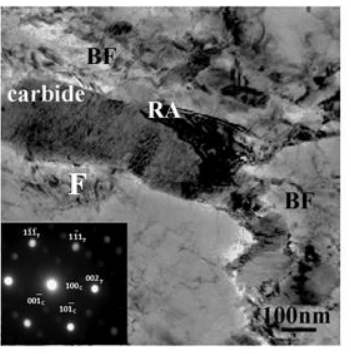

c

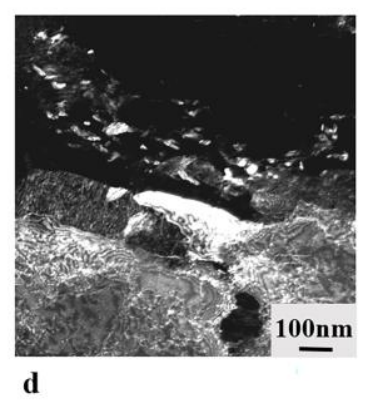



diffraction spot (d) micrographs showing initial microstructure of TRIP steel after $1800 \mathrm{~s}$ isothermal hold at 723K (a), lenticular carbides (b) and decomposed austenite (c, d) in the samples after TMP. Zone axis for (b) is $[2 \overline{1} \overline{1}]$, and for $(c)$ is $[110]_{\gamma} / /[010]_{c}$.

SEM on bulk samples (Fig. 5a) together with EBSD (Fig. 2) and TEM (Fig. 6) after 16 years roomtemperature storage confirmed the following microstructural features: (i) the formation of lamella-like, coarse pearlite between ferrite grains (Figs. 5, 6c), (ii) lamella-like, fine or degenerate pearlite formed at the ferrite/bainite interface, (Figs. 2c, 2d, 6a, 6b) and (iii) the presence of LSC in bainite (Figs. 2d and 6d).

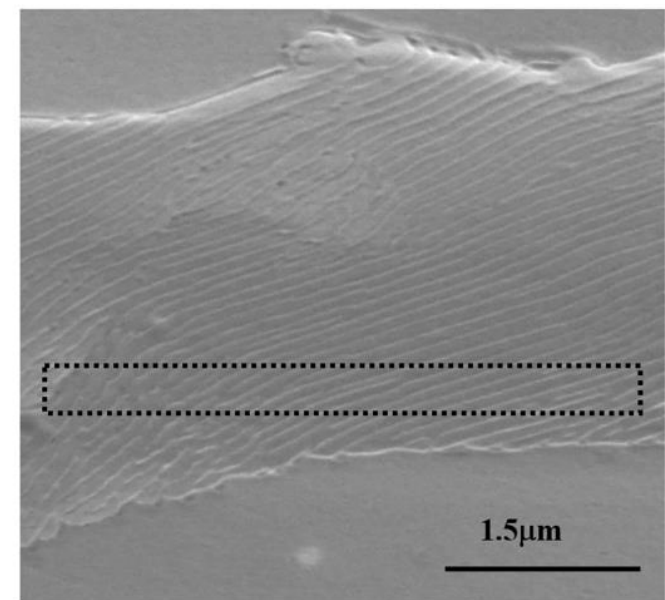

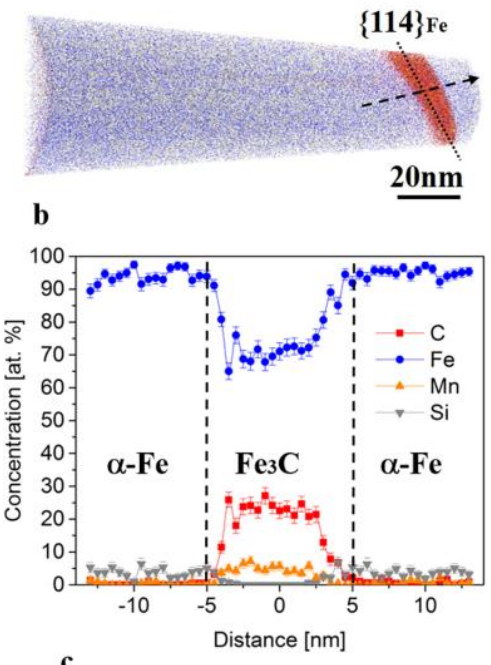

Figure 5. SEM micrograph showing position of APT sample (dash line) taken from pearlite (a), corresponding Fe-C atom map (b) and composition profile across cementite in pearlite (along dash line shown in atom map (b)) (c). and carbides are denoted by red, blue, green and yellow colours which correspond to map areas of $0.18 \%, 69.4 \%, 23.5 \%$ and $0.49 \%$, respectively. The yellow areas (Figs. $2 \mathrm{c}$ and $2 \mathrm{~d}$ ) possess the 
highest carbon content (Fig. 2b) and their morphology correlates with the LSC seen in TEM (Fig. $6 \mathrm{~d})$. The $6.43 \%$ area denoted by the aqua colour comprises the mixed region of martensite, pearlite or secondary formed ferrite via RA decomposition. It is also noted that the aqua areas in the immediate vicinity of a carbide could be a diffusion zone of carbon enrichment; in which case these localised regions could also be carbon enriched BF.

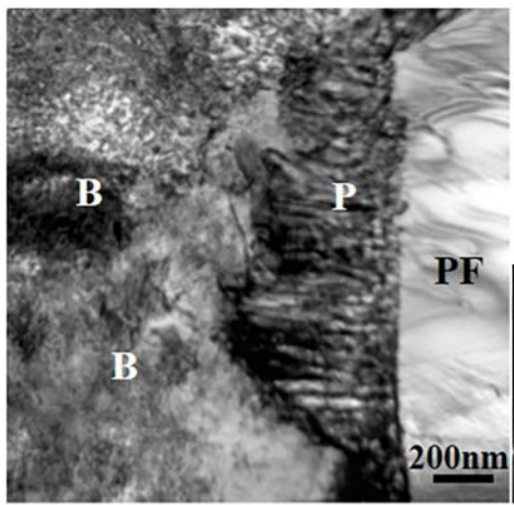

a

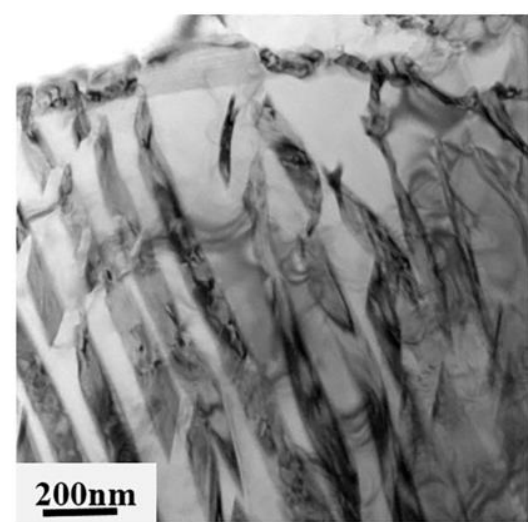

c
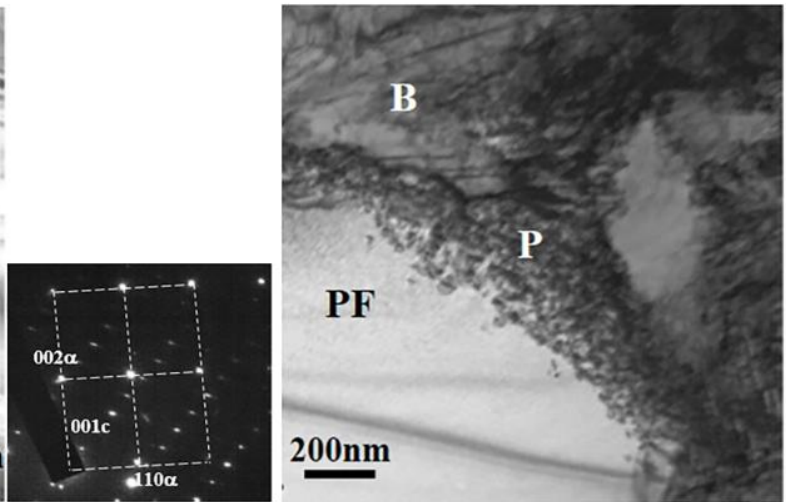

b

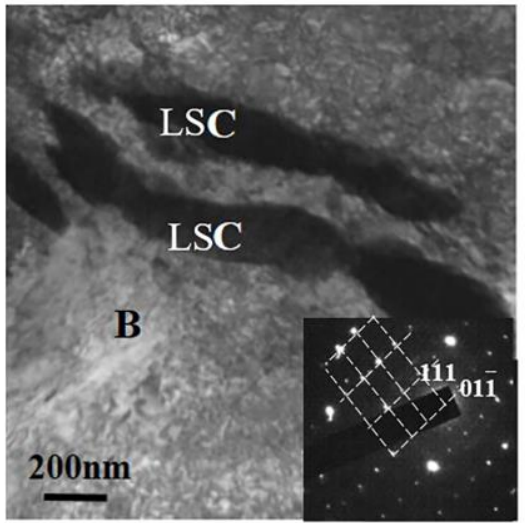

d

Figure 6. Representative TEM micrographs of the microstructure after 16 years in storage: (a) lamella-like ([1-10]a//[-100]c and (b) degenerate pearlite, (c) pearlite in ferrite and (d) presence of LSP in bainite (zone axis is [-2-11]). $\mathrm{PF}$ is polygonal ferrite, $\mathrm{B}$ is bainite, $\mathrm{P}$ is pearlite and LSC is lenticular shape carbides. Note that coarse pearlite is not edge-on in (c) in order to better reveal the cementite layers. 
Two types of pearlite with different inter-lamellar distances were observed: (i) coarse and (ii) fine. The thickness of cementite layers in coarse pearlite was $12 \pm 3 \mathrm{~nm}$, while the thickness of ferrite was $100 \pm 10 \mathrm{~nm}$ (Fig. 5). In the case of fine pearlite (Figs. 6a, and 7), the thickness of cementite was $\sim 10 \pm 2 \mathrm{~nm}$ and the thickness of ferrite was $\sim 50 \pm 5 \mathrm{~nm}$.
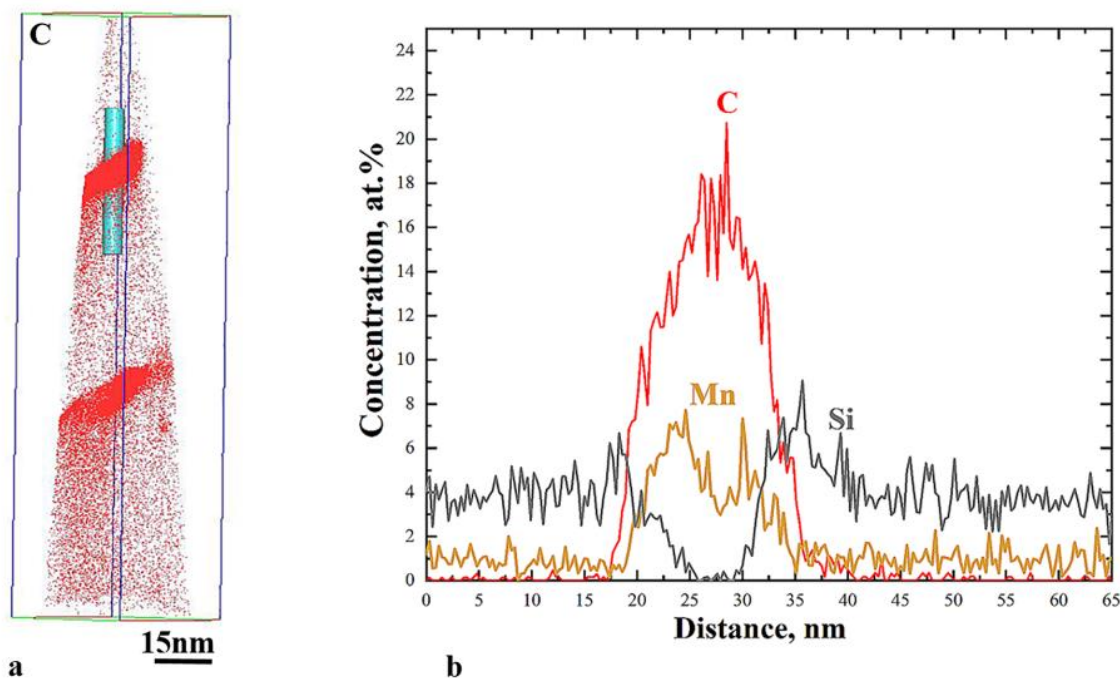

Figure 7. Representative carbon atom map (a) and concentration profile (b) along the box shown in (a) of pearlite from the site specific sample shown in Figure 3.

The carbon atom maps from the site-specific APT needles proved the formation of cementite and ferrite lamellae (Figs. 5b, 5c and 7a). The average cementite and ferrite thicknesses were comparable to that obtained from SEM and TEM data for both coarse and fine pearlite. The average carbon content calculated from the centre of these cementite layers varied from 18 to 27 at.\%; which correlates well with its expected $\sim 25$ at.\% carbon content (Figs. 5c, 7b). The 1D concentration profiles also showed: (i) the partitioning of Mn to cementite (increasing from 1.5 at.\% in ferrite to $\sim 6$ at.\% within the cementite layers) and, (ii) the depletion of $\mathrm{Si}$ in cementite layers to $\sim 0.01$ at.\% compared to $\sim 3.8$ at.\% in ferrite (Figures $5 \mathrm{c}$ and $7 \mathrm{~b}$ ).

Based on APT, it was found that prolonged storage for 16 years affected the redistribution of solutes, mainly carbon, between and within the phases. This occurred in BF and RA/martensite 

due the high dislocation densities of these phases. Firstly, segregation of $\mathrm{C}$ and $\mathrm{Mn}$ at ferrite/bainite interfaces was observed (Fig. 8a).

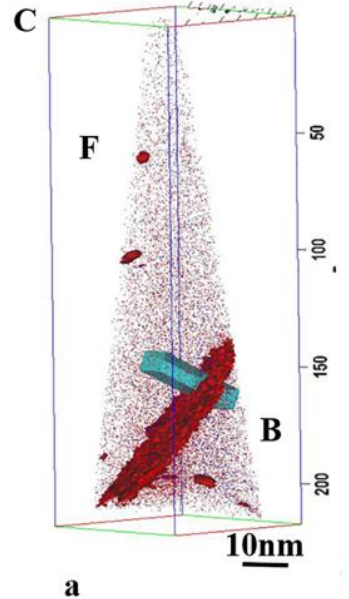

a

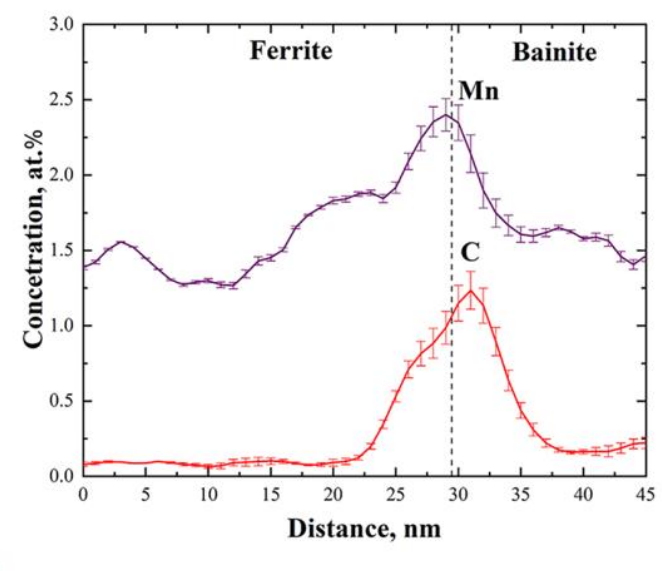

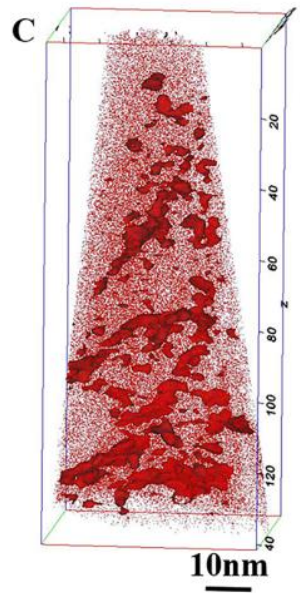

Figure 8. Representative carbon atom map (a, c) and concentration profile (along the box shown in (a)) across ferrite/bainite interface (b); and segregation of $\mathrm{C}$ at dislocations in martensite/retained austenite ( 5 at.\%C iso-surface ) (c). $\mathrm{F}$ is ferrite and $\mathrm{B}$ is bainite.

The local concentration profile along the selected box perpendicular to a ferrite/bainite interface shows an increase in C level from $\sim 0.06 \pm 0.01$ at. $\%$ in the matrix of polygonal ferrite to 1.2 at. $\%$ at the interface. At the same time, the BF continued to be saturated in carbon $(\sim 0.2 \pm$ 0.02 at.\%). The Mn level is 2.4 at.\% at the interface and it gradually decreases to $\sim 1.38 \pm 0.1$ at.\% in the matrix of polygonal ferrite and to $\sim 1.56 \pm 0.08$ at.\% in BF (Figs. 8a, 8b). Secondly, a carbon segregation at dislocations and the formation of carbon clusters in martensite/RA were also found in this condition. (Fig. 8c).

\section{Discussion}


Since maintaining the required level of the RA stability is necessary for TRIP steel sustainability, it is important to study the microstructural changes after prolonged room temperature exposure.

In this regard, the addition of Si to this TRIP steel is important as it typically inhibits the formation of cementite; a process that removes carbon from RA. It follows that inhibiting cementite formation is crucial to the overall stability of RA which increases with the progress of the bainite transformation [39]. However, if the coiling time exceeds the time of the bainite reaction, then the RA can decompose with the formation of secondary ferrite and carbides [29].

The TEM investigation revealed the presence of LSC within bainite after isothermal holding for $1800 \mathrm{~s}$. The morphology of these LSC is dissimilar to $\varepsilon$-carbides or cementite that precipitate rapidly in upper or lower bainite [17]. It also differs from the thin carbide needles formed in BF laths observed after $40 \mathrm{~min}$ holding at $773 \mathrm{~K}$ in a $1.83 \mathrm{Si}$ wt.\% steel [40] such that their formation was ascribed to the secondary stage of the bainite reaction. As these LSC were not a representative feature in the TMP steel with a shorter (600s) holding time at $723 \mathrm{~K}$ (please see Refs. [31, 32] by the same co-authors), and bainite formation was completed in that condition, it could be suggested that the LSC formed by decomposition of residual austenite that was highlyenriched in carbon (4-7at.\%). Previous APT studies of RA in TRIP steels after TMP [25, 31] indicate a wide range of carbon contents depending on its size, location and neighbouring phases as well as the inhomogeneous distribution of carbon within RA. Thus, prolonged exposure at $723 \mathrm{~K}$ enables carbon to continue diffusing from supersaturated BF into RA. Consequently, regions close to BF are enriched in carbon; which triggers the formation of LSC in thin RA layers between BF laths (Fig. 4b) or in part of a coarser RA (Fig. 4c). The part of the RA that is less enriched in C remains stable on cooling to room temperature. These LSC closely resemble the carbides observed by Sandvik [29] where LSC demonstrated extensive faulting and lenticularity and their crystal structure was identified as triclinic or distorted orthorhombic. All of these factors support the hypothesis proposed by Sandvik [29] that the 
formation of such carbides takes place during the decomposition of RA by the shear mechanism. Here it should be noted that a phase forming by a diffusion-controlled mechanism is expected to contain a comparatively lower density of faults [29]. Moreover, it was also suggested by Sandvik [29] that the high density of internal defects in the LSC could be inherited from the stress accumulation in RA that is associated with BF formation.

Based on the above considerations, a proposal for the kinetics of the transformation events occurring during the isothermal holding time is proposed. The nucleation of BF immediately followed by the initiation of its growth, begins the process of carbon partitioning into residual austenite. Since the distribution of carbon is inhomogeneous within and between differently sized morphologies of RA, this phase could possess low, intermediate and supersaturated levels of carbon. In turn, this leads to the RA behaving differently with increased isothermal holding time. Here, the RA with the lowest carbon content easily transforms to martensite during quenching whereas the RA with an intermediate carbon content remains stable at room temperature. It follows then that the RA supersaturated with carbon decomposes, probably by the shear mechanism, to form LSC and secondary ferrite.

In this case, the effect of increasing the isothermal holding time during coiling can be summarized as having two effects. (i) It leads to an increase in the fraction of supersaturated RA, which decomposes easily during subsequent holding. (ii) Alternatively, it increases the overall stability of low carbon RA, which, in turn, inhibits martensite formation during quenching.

The hypothesis that RA contains varying carbon content is strengthened by TEM investigations of the samples after prolonged room-temperature storage. Imaging revealed the presence of pearlite at $\mathrm{BF} /$ polygonal ferrite interfaces or in-between polygonal ferrite grains (Figs. 5a and 6 a-c). However, the EBSD map (Fig. 3c) revealed that not all of the RA decomposed into pearlite, which also indicates the inhomogeneity in carbon content between and within the RA crystals. It is interesting to note that if the area percentages of the red (0.18\%) and aqua (6.43\%) regions 
are summed, the resulting $6.61 \%$ area fraction is similar to the original RA fraction estimated by XRD after TMP. The decomposition of RA following the initial rapid formation of BF has only been studied at elevated temperatures $[23,26,28,29]$. The possibility of RA decomposing into thermodynamically stable ferrite and carbides at room temperature has not been reported to date.

Due to the high rate of carbon diffusion, even at RT, carbon atoms will continue re-arranging with the formation of clusters and Cottrell atmospheres at dislocations in BF (Fig. 8c) competing with carbon diffusion to RA where carbon has higher solubility compared to BF. Since APT studies after TMP showed that carbon content in RA typically exceeds 3 at. $\%$ and can be as high as 7 at.\%, and taking into account that these values could have been increased during several years at RT, equilibrium calculations were conducted in Thermo-Calc to assess the thermodynamic driving force for pearlite formation from RA, $\Delta G_{\text {pearlite }}$, which is defined as:

$$
\Delta G_{\text {pearlite }}=G_{\text {ferrite }}+G_{\text {cementite }}-G_{\text {austenite }}
$$

with $G$ being the Gibbs energy of the phases. The values for $G_{\text {ferrite }}$ and $G_{\text {cementite }}$ are under the assumption that cementite and ferrite partition in para-equilibrium, i.e. only by diffusion of the interstitial element $\mathrm{C}$. The calculation was conducted on the intermediate composition of RA Fe4.80C-1.06Mn-1.40Si at.\%. Fig. 9 shows the molar driving force for pearlite formation from RA as a function of temperature with a step size of $50 \mathrm{~K}$. Driving force and temperature show an inversely proportional relationship in which the driving force increases from 1.0 to $5.5 \mathrm{~kJ} / \mathrm{mol}$ during cooling in the $500 \mathrm{~K}$ temperature interval. The computed driving force supports that the transformation at low temperature is definitely thermodynamically feasible. The pearlite property model in Thermo-Calc [41] was used to attempt an assessment of the experimentallyobserved pearlite formation kinetics. However, since hardly any experimental data on C boundary diffusivity and interfacial mobility is available below $800 \mathrm{~K}$, the calibration of the model was optimized for the temperature range $800-1000 \mathrm{~K}$. Thus, predictions of the kinetics 
of pearlite formation at room-temperature require too much of an extrapolation and are not reliable.

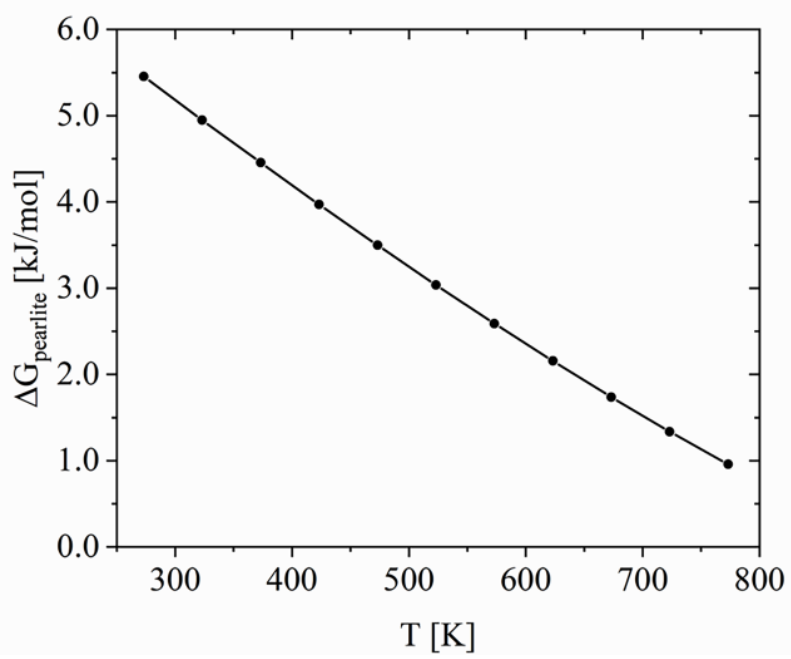

Figure 9. Molar driving force for pearlite formation, $\Delta G_{\text {pearlite }}$, from the intermediate composition of retained austenite under the assumption of para-equilibrium between ferrite and cementite as a function of temperature.

\section{Conclusions}

Lenticular shape carbides with high density of internal defects were found after isothermal holding for $1800 \mathrm{~s}$ and after 16 years storage at room temperature. It was suggested that the carbides were formed as a result of decomposition of residual austenite. This austenite is located in close proximity to BF and enriched in carbon. Partial RA decomposition with pearlite formation was observed in TRIP steel after 16 years storage at room temperature. This supports the inhomogeneity in the distribution of carbon within and between RA grains based on their morphology and location in a TMP TRIP steel. Furthermore, it posed the question regarding the longtime RA stability under service conditions and its effect on component properties. ThermoCalc calculations support the feasibility of pearlite formation from the RA due to a high thermodynamic driving force for its formation. 
430

431

432

433

434

435

436

437

438

439

440

441

442

443

444

445

446

447

448

449

450

451

452

453

454

455

456

457

458

459

460

461

462

463

464

465

466

467

468

The authors would like to acknowledge the financial support of Deakin University and the University of Wollongong, Australia. Deakin University's Advanced Characterisation Facility is acknowledged for use of the FIB-SEM, TEM, and APT. The JEOL JSM-7001F at the UOW-EMC was funded by the Australian Research Council - Linkage, Infrastructure, Equipment and Facilities grant LE0882613. The Oxford Instruments $80 \mathrm{~mm}^{2} \mathrm{X}$-Max EDS detector was funded via the 2012 UOW Major Equipment Grant scheme. A. Gazder acknowledges the 2019 AIIM for Gold - Investigator grant.

\section{References}

[1] B.C. De Cooman, Curr. Opin. Solid State Mater. Sci., 2004, vol. 8(3-4), pp. 285-303.

[2] P.J. Jacques, Curr. Opin. Solid State Mater. Sci., 2004, vol. 8, pp. 259-265.

[3] O. Matsumura, Y. Sakuma, H. Takechi, Scripta Metall., 1987, vol. 21, pp. 1301-1306.

[4] I.B. Timokhina, P.D. Hodgson, E.V. Pereloma, Metall. Mater. Trans. A, 2004, vol. 35A(8), pp. 2331-2341.

[5] E. Pereloma, H. Beladi, L. Zhang, I. Timokhina, Metall. Mater. Trans. A, 2012, vol. 43A, pp. 3958-3971.

[6] F.G. Caballero, H.K.D.H. Bhadeshia, K.J.A. Mawella, D.J. Jones, P. Brown, Mater. Sci. Technol., 2002, vol. 18(3), pp. 279-284.

[7] F.G. Caballero, H.K.D.H. Bhadeshia, Curr. Opin. Solid State Mater. Sci., 2004, vol. 8(3), pp. 251257.

[8] F. Caballero, C. Garcia-Mateo, M. Miller, Mater. Sci. Technol., 2015, vol. 31, pp. 764-772.

[9] J. Speer, D.K. Matlock, B.C. De Cooman, J.G. Schroth, Acta Mater., 2003, vol. 51(9), pp. 26112622.

[10] D.V. Edmonds, K. He, F.C. Rizzo, B.C. De Cooman, D.K. Matlock, J.G. Speer, Mater. Sci. Eng. A, 2006, vol. 438-440, pp. 25-34.

[11] L. Liu, B. He, G.-J. Cheng, H.-W. Yen, M.X. Huang, Scr. Mater. 2018, vol. 150, pp. 1-6.

[12] X. Tan, D. Ponge, W. Lu, Y. Xu, X. Yang, X. Rao, D. Wu, D. Raabe, Acta Mater., 2019, vol. 165, pp. 561-576.

[13] T. Furukawa, H. Huang, O. Matsumura, Mater. Sci. Technol., 1994, vol. 10, pp. 964-970.

[14] D.W. Suh, J.H. Ryu, M.S. Joo, H.S. Yang, K. Lee, H.K.D.H. Bhadeshia, Metall. Mater. Trans. A, 2013, vol. 44A, pp. 286-293.

[15] Y.-K. Lee, J. Han, Mater. Sci. Technol., 2015, vol. 31(7), pp. 834-856.

[16] H.K.D.H. Bhadeshia, D. Edmonds, Metall. Trans. A, 1979, vol. 10, pp. 895-907.

[17] H.K.D.H. Bhadeshia, Bainite in Steels: Transformations, Microstructure and Properties, Second ed. ed., Institute of Materials, Minerals and Mining, London, 2001.

[18] E. Pereloma, A.A. Gazder, I. Timokhina, Retained austenite: transformation-induced plasticity, in: R. Colas, G.E. Totten (Eds.) Encyclopedia of Iron, Steel, and Their Alloys, CRC Press, New York, 2016, pp. 3088-3103.

[19] E. De Moor, D.K. Matlock, J.G. Speer, M.J. Merwin, Scr. Mater.,2011, vol. 64(2), pp. 185-188. 
[20] A.S. Podder, I. Lonardelli, A. Molinari, H.K.D.H. Bhadeshia, Proc. R. Soc. A, 2011, vol. 467, pp. $470 \quad 3141-3156$

471 [21] W. Shi, L. Li, B.C. De Cooman, P. Wollants, C.-X. Yang, J. Iron Steel Res. Int., 2008, vol. 15, pp. 472 61-64.

[22] C. Lerchbacher, S. Zinner, H. Leitner, Mater. Sci. Eng. A, 2013, vol. 564, pp. 163 - 168.

[23] A.S. Podder, H.K.D.H. Bhadeshia, Mater. Sci. Eng. A, 2010, vol. 527(7), pp. 2121 - 2128.

[24] C. Garcia-Mateo, F.G. Caballero, M.K. Miller, J.A. Jimenez, J. Mater. Sci., 2012, vol. 47(2) pp. 1004-1010.

[25] Z.P. Xiong, A.A. Saleh, R.K.W. Marceau, A.S. Taylor, N.E. Stanford, A.G. Kostryzhev, E.V. Pereloma, Acta Mater., 2017, vol. 134, pp. 1 - 15.

[26] H.-S. Park, J.-B. Seol, N.-S. Lim, S.-I. Kim, C.-G. Park, Mater. Des., 2015, vol. 82, pp. 173 - 180.

[27] Y.K. Lee, H.C. Shin, Y.C. Jang, S.H. Kim, C.S. Choi, Scr. Mater., 2002, vol. 47(12), pp. 805 - 809. [28] F.G. Caballero, C. Garcia-Mateo, C. Garcia de Andres, Metall. Trans. A, 2005, vol. 46(3), pp. 581-586.

[29] B.P.J. Sandvik, MTA, 1982, vol. 13(5), pp. 777-787.

[30] I.B. Timokhina, P.D. Hodgson, E.V. Pereloma, in: E.F. Palmiere, M. Mahfouf, C. Pinna (Eds.) International Conference on Thermomechanical Processing: Mechanics, Microstructure \& Control, Sheffield University, UK, 2003, pp. 115-121.

[31] E.V. Pereloma, I.B. Timokhina, M.K. Miller, P.D. Hodgson, Acta Mater., 2007, vol. 55(8), pp. 2587-2598.

[32] I.B. Timokhina, E.V. Pereloma, P.D. Hodgson, Mater. Sci. Technol., 2001, vol. 17(2), pp. 135140.

[33] B.D. Cullity, Elements of x-ray diffraction, Addison-Wesley Publishing Company, Inc., Reading, MA, 1978.

[34] A.A. Gazder, F. Al-Harbi, H.T. Spanke, D.R.G. Mitchell, E.V. Pereloma, Ultramicroscopy, 2014, vol. 147, pp. 114-132.

[35] C. Sommer, C. Straehle, U. Koethe, F.A. Hamprecht, Ilastik: Interactive Learning and Segmentation Toolkit, IEEE International Symposium on Biomedical Imaging, doi:10.1109/ISBI.2011.5872394. ISBN 978-1-4244-4127-3, 2011, pp. 230-33.

[36] M.K. Miller, R.G. Forbes, Atom-Probe Tomography: The Local Electro Atom Probe, Springer, New York, 2014.

[37] J.O. Andersson, T. Helander, L. Höglund, P. Shi, B. Sundman, Calphad, 2002, vol. 26(2), pp. 273-312.

[38] Y. Hirotsu, S. Nagakura, Acta Metall., 1972, vol. 20(4), pp. 645-655.

[39] H.K.D.H. Bhadeshia, Acta Metall., 1980, vol. 28(8), pp. 1103-1114.

[40] Y.C. Jung, Y. Ohomori, K. Nakai, H. Ohtsubo, ISIJ Int., 1997, vol. 37(8), pp. 789-796.

[41] J.-Y. Yan, J. Ågren, J. Jeppsson, Metall. Trans. A, 2020, accepted. 